\title{
A Prospective Study of 50 Cases of Familial Parkinson's Disease
}

\author{
Madeleine Roy, Liette Boyer and André Barbeau
}

\begin{abstract}
SUMMARY: In a recent paper (Barbeau and Pourcher, 1982) we demonstrated that so-called "idiopathic" Parkinson's disease is not a homogeneous entity, and defined the existence of a sub-group of patients with genetic parkinsonism. To investigate this last possibility, and to uncover possible metabolic clues as to the etiology of such cases, we carried out a prospective study of 50 kindreds with "familial" parkinsonism. Two control groups were similarly studied: 50 kindreds with essential tremor (neurological control group) and 50 kindreds originating from spouses of the previous patients (non neurological control group). We uncovered two main patterns of genetic transmission within the parkinsonian patients: a parkinsonism related to dominant essential tremor ( 34 kindreds; $10 \%$ of all Parkinsonians) and a recessive "akineto-rigid syndrome" (10 kindreds; 3-4\% of all Parkinsonians). A further 4 kindreds assumed a pseudo-dominant pattern but were probably recessive. Finally 2 kindreds were obviously other entities presenting as "phenocopies" of Parkinson's disease. Metabolically, hyperthyroidism appeared to be more frequent in essential tremor and "essential-tremor related parkinsonism" kindreds, while hypothyroidism and possibly hypoparathyroidism (post surgery) seemed more frequent in the recessive akineto-rigid syndrome kindreds.
\end{abstract}

RÉSUMÉ: Lors d'une publication récente (Barbeau et Pourcher, 1982) nous avons démontré que la maladie de Parkinson "idiopathique" n'est pas une entité homogène, délimitant en fait un sous-groupe à caractère génétique. Afin d'investiguer plus à fond cette possibilité, et de découvrir des indices métaboliques sur l'étiologie de la maladie, nous avons effectué une étude prospective de 50 familles avec Parkinson familial. Nous avons également étudié deux groupes contrôles: 50 familles avec tremblement essentiel et 50 familles témoins (conjoints des premiers). Nous avons découvert deux principaux modes de transmission génétique chez les parkinsonniens: un Parkinson relié au tremblement essentiel dominant (34 familles; $10 \%$ des cas de Parkinson) et un Parkinson récessif, de type akinéto-rigide (10 familles; $3-4 \%$ des cas de Parkinson). Dans quatre autres familles la maladie se présentait comme pseudo-dominante mais était probablement récessive, alors que 2 familles étaient clairement atteintes d'autres entités, "phénocopies" du Parkinson. Métaboliquement nous avons retrouvé l'hyperthyroidie avec fréquence augmentée dans les familles de tremblement essentiel et le Parkinson associé au tremblement essentiel, alors que l'hypothyroidie, et peut-être l'hypoparathyroidie, semble être plus fréquente dans la forme récessive du syndrome akinéto-rigide.

Can.J. Neurol. Sci. 1983; 10:37-42

The problem of the heritability of Parkinson's disease has been discussed for many years with variable conclusions (Allan, 1937; Mjones, 1949; Kondo et al, 1973; Martin et al., 1973; Kessler, 1978). Most of the ambiguity probably derived from the fact that all authors considered "idiopathic Parkinson's disease" as a single homogeneous entity. This dogma was challenged by us in a recent study (Barbeau and Pourcher, 1982).

We investigated the clinical and metabolic characteristics of Parkinsonian patients whose illness started before the age of 40. A pilot study of 32 of our own such cases revealed the existence of 3 sub-groups: 1) post-encephalitic; 2) onset and course with predominant tremor; 3 ) onset and course with akinesia and rigidity. In this group of patients with early onset, there was a $46 \%$ incidence of familial cases (as opposed to $10-15 \%$ in the general $\mathrm{Parkinsonian}$ population). The cases with tremor as the initial symptom had a high prevalence of essential tremor in their families, while those who presented with an akineto-rigid syndrome had a high familial incidence of other cases of Parkinson's disease. Familial grey hair, hypertension, diabetes and thyroidopathies occurred at higher than expected frequencies.

These trends were confirmed in a larger series of 135 cases of early onset Parkinson obtained through a mail survey. When the same clinical material was analysed for the familial cases only, two new genetic sub-groups emerged: 1) a familial metabolic akineto-rigid syndrome (with hypertension, familial diabetes, hypothyroidism and a more severe course) and, 2) a familial essential tremorrelated Parkinsonian syndrome (with familial grey hair trait and hyperthyroidism). Previous investigations from Japan (Yokochi and Narabayashi, 1981) had also delineated a form of familial juvenile Parkinsonism. It was concluded that the so-called "Parkinson's Syndrome" is not a single homogeneous entity and a new classification was proposed for that syndrome: Type I: Post encephalitic; Type II: Idiopathic; Type III: Genetic and; Type IV: Symptomatic.

The present study was designed to investigate in more detail the various observations previously made by us, and to gather more evidence for understanding the familial type of Parkinson's disease. To accomplish this we carried out a prospective study of 50 consecutive familial aggregations of Parkinson's disease, and compared the findings to those obtained from a similar investigation of 50 consecutive cases of familial essential tremor and of 50 consecutive nonneurological controls chosen from among spouses of the previous patients. 


\section{RESULTS AND DISCUSSION}

The Movement Disorder Clinic of the Clinical Research Institute of Montreal has an active roster of 342 parkinsonian patients and a total list of 643 parkinsonian patients. The clinic also follows 135 cases of essential tremor. From this clinical material, and a certain number of recently referred new cases, we carried out detailed interviews surveying the family history of all patients, and investigated a number of metabolic parameters. 50 cases of "familial" Parkinson's disease were thus identified. Two control groups were also studied: A neurological control group consisting of 50 consecutive cases of familial essential tremor and a non-neurological control group of 50 spouses of similar age to the Parkinsonian patients. Data were obtained on members of the immediate family of the patient (father, mother, siblings and children) and of the extended family (grand-parents, uncles and aunts, cousins). As seen in Table 1 approximately equal numbers of family members were surveyed in both groups, although the totals are slightly lower for the "normal" control group.

The distribution of familial aggregations of Parkinson's disease cases in the 50 families is tabulated in Table 2. Most authors have minimized the importance of these familial aggregations on the basis that Parkinson's disease is so frequent that they could be accounted for by chance alone. Based on the average immediate family size observed in our study (see Table 1), our 342 active Parkinsonian patients would have approximately 4500 immediate family members. Assuming that the prevalence of Parkinson's disease in such a group is $1 / 1000$, as it is estimated to be in the general population, approximately 5 other cases of Parkinson's disease would have been expected. This figure would have been 9 for the total list of 643 Parkinsonian patients. In this material we actually found 50 families with multiple cases of essential tremor or Parkinson's disease. As seen in Table 3, within these kindreds where the index case always had idiopathic Parkinson's disease, there were 30 additional cases of Parkinson's disease and 100 cases of essential tremor. This should be compared to 8 additional cases of Parkinson's disease in 50 kindreds with essential tremor in the index case, and 5 additional cases in the control families. These figures for Parkinson's disease are minimal because when the slightest doubt existed, the diagnosis was always given as essential tremor. However one should recognize that the weakness of these calculations is the value assigned to prevalence rates, which have been variously estimated (see Martilla and Rinne, 1976). A better indication of the existence of familial aggregations is the observed grouping of cases within family units. A grouping of 2 cases of Parkinson's disease within a kindred could be due to chance alone, but this factor would provide for only one instance of 3 or more cases of Parkinsons' disease in the same kindred within this material. The actual observation of 5 such multiple-case families ( 3 or more cases of Parkinson's disease) is a strong argument in favor of our thesis of the existence of genetic sub-groups of idiopathic Parkinson's disease, and the present study thus confirms our working hypothesis (Table 2).

Assuming that "Parkinson's disease" is not a homogeneous disorder and that a genetic subgroup exists, as shown above, one should not conclude that even this gene-

\begin{tabular}{|c|c|c|c|}
\hline & \multicolumn{2}{|c|}{$\begin{array}{c}\text { TABLE I } \\
\text { Investigated Families }\end{array}$} & \multirow[b]{2}{*}{ Controls } \\
\hline & Parkinson & $\begin{array}{l}\text { Essential } \\
\text { Tremor }\end{array}$ & \\
\hline No. Families & 50 & 50 & 50 \\
\hline $\begin{array}{l}\text { Immediate family } \\
\text { members }\end{array}$ & 648 & 541 & 466 \\
\hline $\begin{array}{l}\text { Extended family } \\
\text { members }\end{array}$ & 2550 & 2311 & 1803 \\
\hline
\end{tabular}

TABLE 2

Distribution of Familial Aggregations

(index case has Parkinson's Disease)

No. of
Kindreds
(50) Sub-Total

A. Parkinson Only

a) 2 cases in kindred

9

b) $\mathbf{3}$ cases in kindred

c) 5 cases in kindred

12

B. Parkinson (P) and Essential Tremor (ET)

a) 2 cases P and 1 of ET
b) - and 2 of ET
c) - and 3 of ET
d) 3 cases P and 2 of ET

6

10

C. Parkinson and Essential Tremor

a) Index case of $P$ and 1 of ET 9

b) - 2 of ET 4

c) - 3 of ET 7

d) - 4 of ET 4

e) - 8 of ET 2

f) $\quad-9$ of ET 2

28

TABLE 3

Incidence of Additional Cases

in Kindred

Immediate Family Distant Family

Parkinson E.T. Parkinson E.T.

$\begin{array}{lrrrr}\begin{array}{l}\text { A. } 50 \text { Kindreds } \\ \text { with Parkinson }\end{array} & 19 & 48 & 11 & 52 \\ \begin{array}{l}\text { B. } 50 \text { Kindreds } \\ \text { with Essential Tremor }\end{array} & 3 & 112 & 5 & 66 \\ \begin{array}{l}\text { C. } 50 \text { Control } \\ \quad \text { Kindreds }\end{array} & 2 & 3 & 3 & 3\end{array}$


TABLE 4

ADULT ONSET GENETIC

"PARKINSON'S DISEASE"

Observed Patterns of Transmission

\section{A. DOMINANT PATTERN}

(a) Tremor predominance

1. Essential tremor related parkinsonism

(34 kindreds)

2. Possible phenocopies (associated entities)

(2 kindreds)

(b) Akineto-rigid predominance

1. Possible pseudo-dominance (only 2 generations) (4 kindreds)

\section{B. RECESSIVE PATTERN}

(a) Generally akineto-rigid or mixed form

(10 kindreds)

tic sub-group is of homogeneous nature. Our own material, as well as that in the literature, clearly indicates that many genetic patterns can be observed.

As seen in Table 4, we have been able to identify a series of distinctive patterns based on the mode of transmission and on the clinical picture:

(A) Dominant pattern with predominance of tremor. This pattern was present in 36 of the 50 Parkinsonian families studied.

(a) the most frequent presentation is the one which we described in our previous paper and termed "Essential tremor related Parkinsonism". In such families the index case is always a definite case of Parkinsonism, generally of the tremor predominant type. This was so in 34 kindreds. In these groupings the transmission of the tremor trait is clearly dominant and the appearance of Parkinsonism appears to be random, possibly with some relationship to hyperthyroidism in the immediate family. Examples of these entities are given in Figs. 1-3.

(b) Possible "phenocopies" with a dominant pattern, and tremor as the main sign, can also be seen. In this

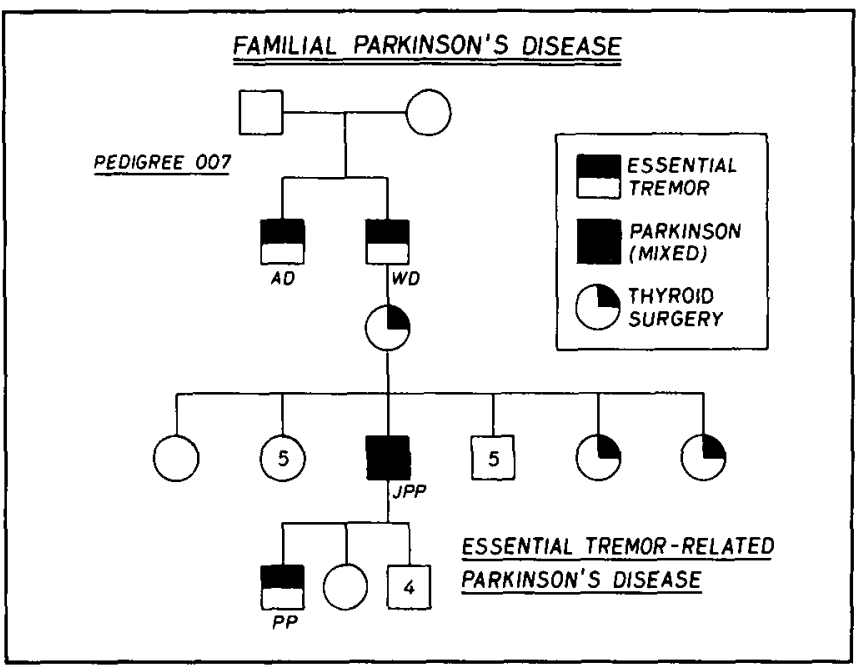

Figure 1 - Pedigree of a kinship with essential tremor and the development of full blown Parkinson's disease in association with familial thyroidopathy.

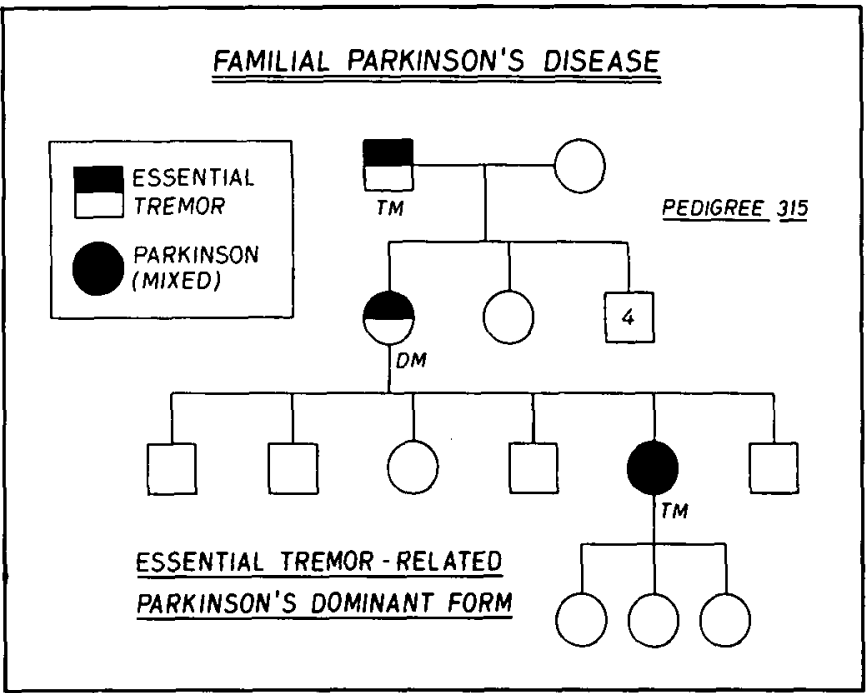

Figure 2 - Parkinson's disease in association with hereditary essential tremor.

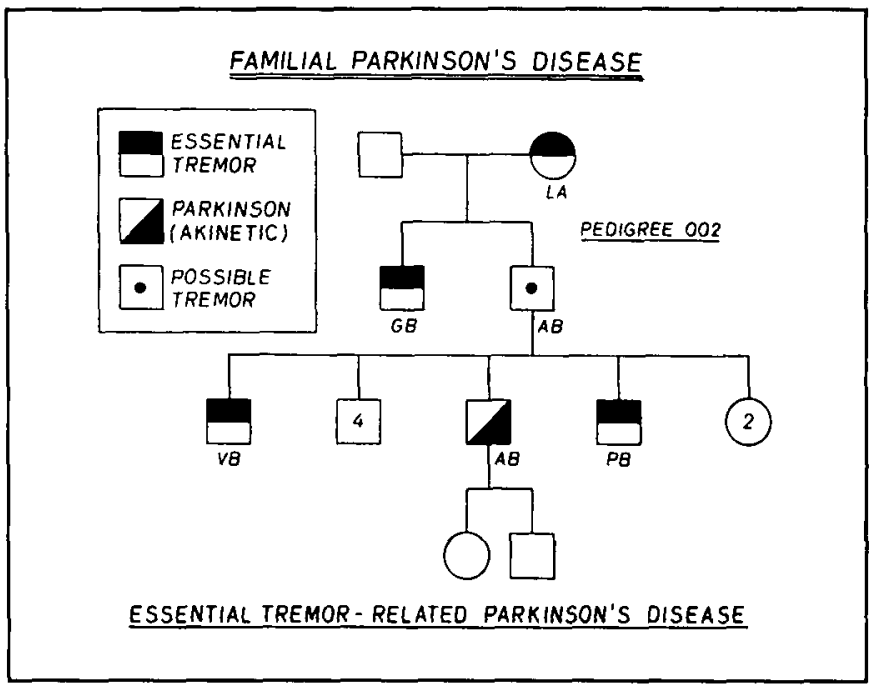

Figure 3 - Parkinson's disease in association with hereditary essential tremor over 3 generations.

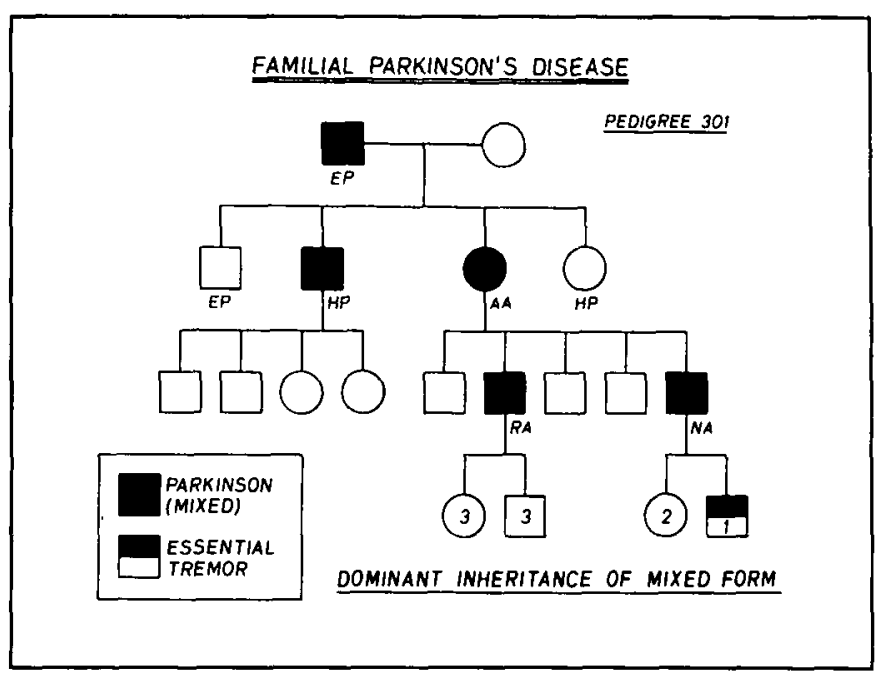

Figure 4 - Mixed form (tremor predominance) of Parkinson's disease over at least 3 generations and in association with severe depressive illnesses. 
group we include families with Parkinsonism and depression such as the kindreds described by Perry et al (1975); Tune et al (1982) and the one illustrated in Fig. 4 and described in the legend. Although we did not encounter the following entities in our own series, it is well known that cases of Parkinsonism could also occur in association with olivo-ponto-cerebellar atrophy, and in the so-called "Joseph disease" of the Azores (Romanul et al, 1977). In all these instances it appears that the presence of the underlying genetic entity is a predisposing factor to the development of the Parkinsonian state. Two of our 50 families can thus be classified as phenocopies with a dominant pattern.

(B) Dominant pattern with akineto-rigid predominance. In this group of 4 families the clinical presentation is that of severe akinetic parkinsonism. As seen in Fig. 5 the pattern observed is always that of a single affected parent with many affected children. In none of our 4 family groups did we note affected relatives in a third generation. In these kinships often originating from regions of known high consanguinity, it is possible that we are dealing with instances of pseudo-dominance, ie. recessively inherited entities seen over 2 generations. Only further studies will permit clarification of this point.

(C) Recessive pattern with akineto-rigid predominance. In 10 of our families, as illustrated in Figs. 6-9, there were two or more clinically identical cases of Parkinsonism within the same kinship. In almost all cases the predominant symptoms were akinesia and rigidity with little or no tremor. When tremor was present, it was as part of the triad we call the "mixed form" (Fig. 8). Occasionally, some members of these recessive kinships were noted to have very mild essential tremor (See Fig. 9). In these 10 kinships the disease was always severe, and progressed rapidly. Women appeared to be even more severely affected than men.

Thus in this prospective study of 50 families with "familial" parkinsonism, we encountered again the two main categories which we had described in our previous

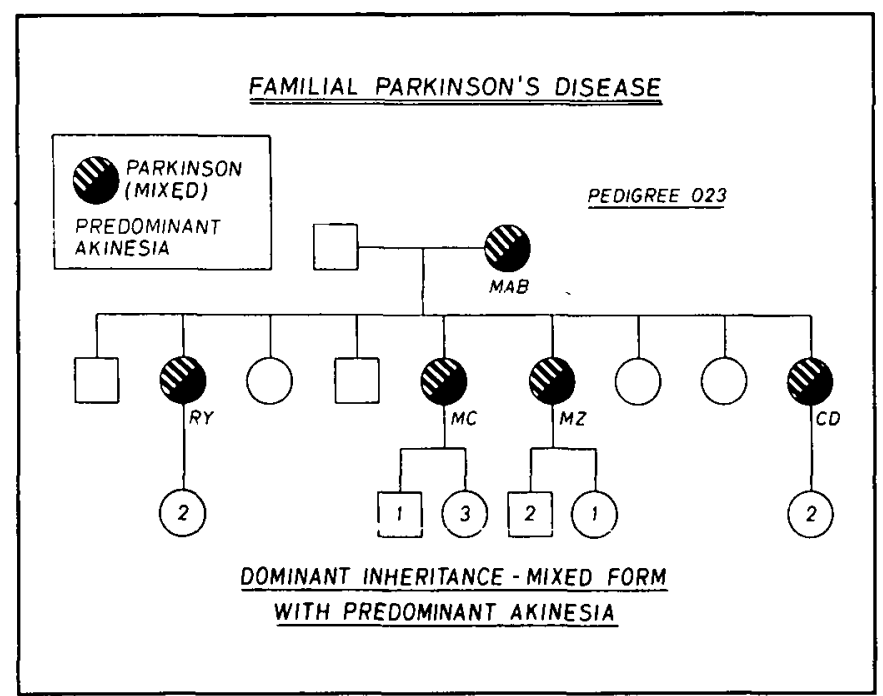

Figure 5 - Probably "pseudo-dominant" form of akineto-rigid parkinsonism in a kindred from an area with high consanguinity in Italy.

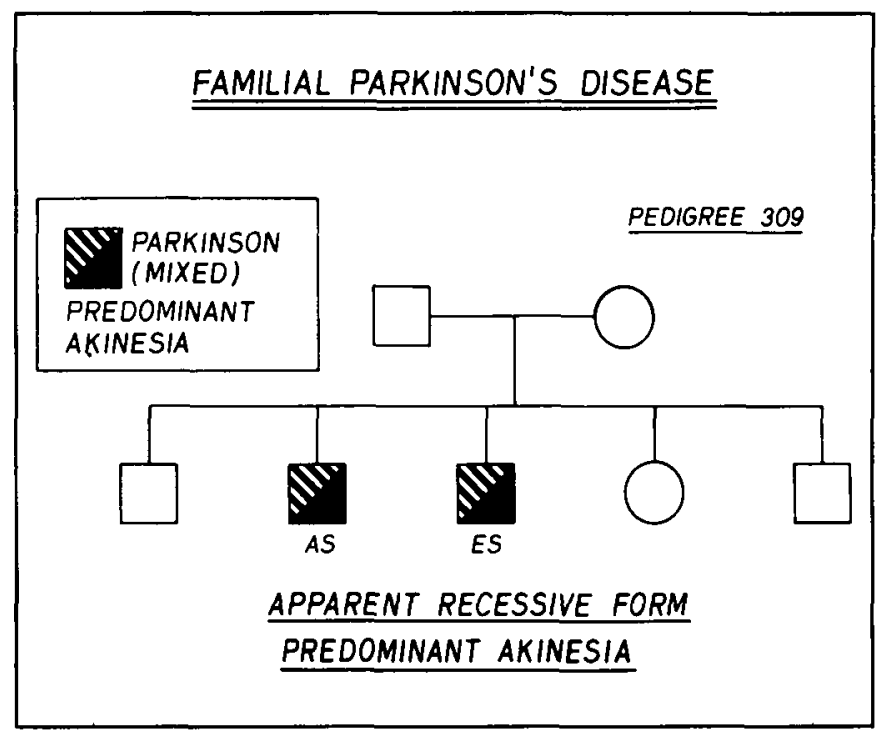

Figure 6 - Recessive akineto-rigid form of Parkinson's disease in siblings.

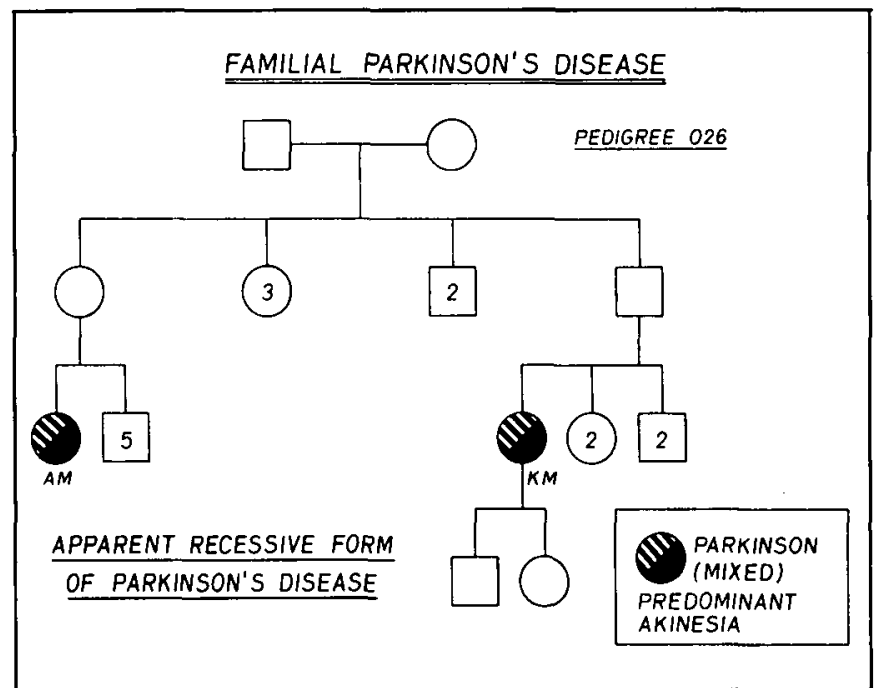

Figure 7 - Recessive akineto-rigid form of Parkinson's disease in cousins.

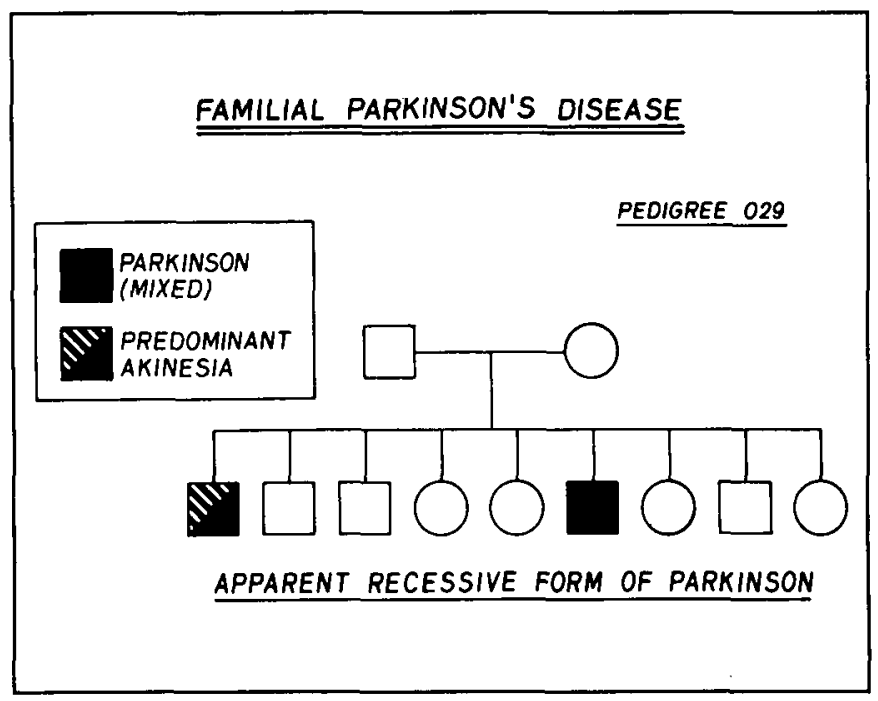

Figure 8 - Recessive akineto-rigid form of Parkinson's disease in siblings. 


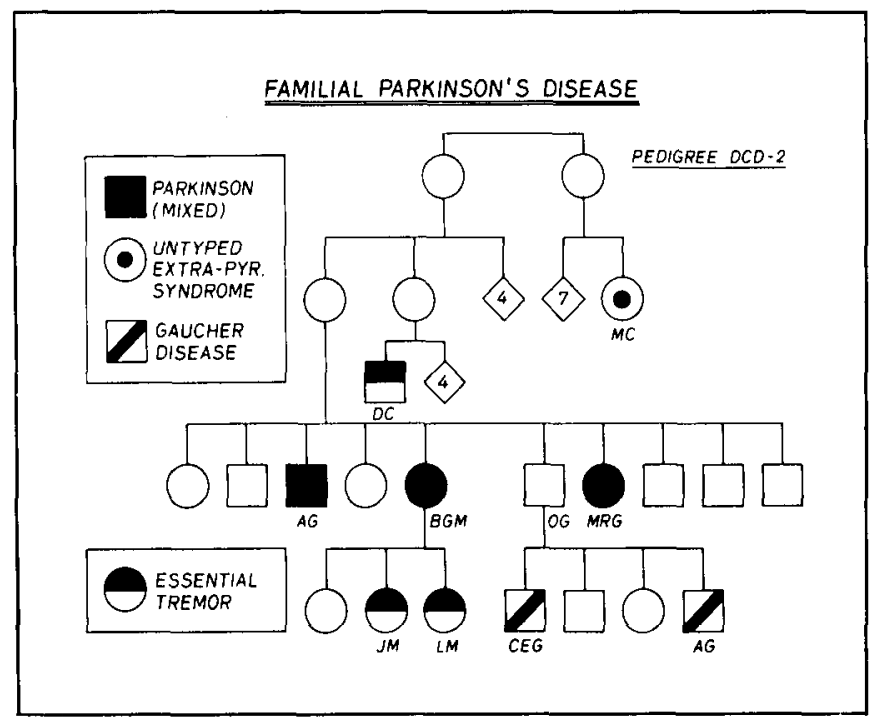

Figure 9 - Recessive akineto-rigid form of Parkinson's disease in siblings. Note the presence of 2 cases of Gaucher disease in the offsprings of a brother of the affected cases, as well as essential tremor in a cousin and in children of one of the patients.

paper: The "Essential-tremor related Parkinsonism" - 34 kinships, and the "Familial akineto-rigid syndrome" - 10 kinships, with the possible addition of 4 more "pseudodominant" kinships. Only two kinships would fall outside this description, and both were probably examples of other entities mimicking Parkinson's disease, thus "phenocopies" with a dominant pattern of inheritance. It is probable that these new categories, which can be separated on clinical and on genetic grounds, are in fact different disorders:

1. An "essential-tremor related Parkinsonism", where tremor as the main symptom is inherited as a dominant trait. This group is estimated to represent $10 \%$ of all cases of "Idiopathic" Parkinson's disease.

2. A recessive "akineto-rigid syndrome", representing 3$4 \%$ of all cases, and possibly more if known akinetic "singlets" are included.

Both disorders deserve detailed studies, first to find which "trigger" factor or factors can transform a dominantly inherited essential tremor into full-blown Parkinson's disease and secondly to unravel the metabolic and enzymatic characteristics of the recessive akineto-rigid form. It is now per-

\section{TABLE 5 \\ CLASSIFICATION OF "PARKINSONISM" (1982)}

\section{TYPE I: $\quad$ Post encephalitic}

\section{TYPE II: Idiopathic}
a) Tremor predominance
b) Akineto-rigid predominance

TYPE III: Genetic
a) Parkinsonism related to dominant essential tremor
b) Recessive "akineto-rigid syndrome"
c) Familial juvenile Parkinsonism
d) Dominant "Parkinsonism" with depression

\section{TYPE IV: Symptomatic}

missible to present a new classification of Parkinsonism, including four distinct genetic entities (Table 5).

\section{PRELIMINARY METABOLIC INVESTIGATIONS}

Our study was designed to verify some of the previously observed correlations within the sub-groups of "genetic" Parkinsonism, such as the high incidence of diabetes, hypertension, thyroidopathies, and familial grey hair (Barbeau and Pourcher, 1982). Because such entities are fairly common in the general population, it was essential to have control groups. As previously stated, we investigated 50 kinships where the index case was diagnosed as "essential tremor" (the neurological control group) and another 50 kinships forming the "non-neurological control group". In the latter instance the index case was the spouse of one of the Parkinsonian patients, or of one of the essential-tremor cases. The same detailed questionnaire was administered to all informants in each of the 3 groups.

As can be seen in Table 6, a slightly higher consanguinity rate is observed in the Parkinson group than in the control group. This could be the basis for our recessively inherited

TABLE 6

Incidence of Traits in Extended Families Surveyed (no. per 1000)

\begin{tabular}{lccc} 
& \multicolumn{3}{c}{ Essential } \\
No. Families & 50 & 50 & 50 \\
Subjects surveyed & 2550 & 2311 & 1803 \\
Consanguinity & $7(2.7)$ & $5(2.1)$ & $3(1.6)$ \\
Diabetes & $38(14.9)$ & $53(22.9)$ & $28(15.5)$ \\
Hypertension & $20(7.8)$ & $51(22.0)$ & $46(25.5)$ \\
Cancer & $56(21.9)$ & $54(23.3)$ & $31(17.2)$ \\
Vitiligo & $\mathbf{5 ( 1 . 9 )}$ & $1(0.4)$ & $0(0.0)$ \\
Early grey hair & $16(6.2)$ & $1(\mathbf{0 . 4 )}$ & $24(13.3)$ \\
Goitre \& hyperthyroidism & $\mathbf{2 9 ( 1 1 . 3 )}$ & $\mathbf{2 6 ( 1 1 . 2 )}$ & $11(6.1)$ \\
Hypothyroidism & $4(1.6)$ & $2(0.8)$ & $5(2.7)$
\end{tabular}

\section{TABLE 7}

Thyroid Status in Families

(no. of cases detected)

\section{Parkinson}

No. families
Thyroid cancer
"Goitre" surgery
Hyperthyroid
Hypothyroid
Total "Thyroid"
Dysfunction

$\begin{array}{cccc}\text { Tremor } & \begin{array}{c}\text { Akineto- } \\ \text { Rigid }\end{array} & \begin{array}{c}\text { Essential } \\ \text { Tremor }\end{array} & \begin{array}{c}\text { Controls } \\ 29\end{array} \\ 21 & 50 & 50 \\ 1 & 0 & 1 & 0 \\ 4 & 14 & 8 & 9 \\ 6 & 4 & 17 & 2 \\ 3 & 1 & 2 & 5\end{array}$

14 19 $33^{*}$ 28 16 
akineto-rigid sub-group. Contrary to previous observations, no statistically significant increases were seen in the incidence of diabetes, cancer or familial grey hair amongst the extended families of the Parkinsonians, even when these features were present in the patients themselves. However it is of interest that hypertension occurs less frequently in these families than in the general population. For some unknown reason, vitiligo (which is fairly common in Parkinson's disease patients) is slightly more frequent within their families. The numbers, however, are much too small to draw any worthwhile conclusions.

The only factor which appears to be present with significantly increased incidence in Parkinson's disease families (and also in essential tremor kindreds) is thyroid dysfunction. This was noted 33 times within the families of Parkinsonian cases $(12.9 / 1000)$ as opposed to 16 times $(8.8 / 1000)$ in non neurological families, thus confirming our initial report (Barbeau and Pourcher, 1982). Table 7 looks at this correlation more closely and particularly in relation to the predominant symptom in the index case. It is seen that "goitre" surgery (presumably for hyperthyroidism) was performed on family members of 18 Parkinsonian patients (twice as many as in the control group) and a further 10 family members were being treated for hyperthyroidism (as opposed to 2 in the control families). Thus 28 possible instances of hyperthyroidism were encountered in the Parkinson kinships, 26 in the essential tremor families and only 11 in the control groups. These differences are significant. One other relationship which we had suspected in our previous study is that dysthyroidism in essential-tremor families could be associated with the transformation of the initial rapid tremor into a slower "Parkinsonian-type" tremor. This may be through changes in dopamine receptor reactivity induced by the thyroid hormone. However when the hyperactive goitre is removed, something happens that favours the development of akinesia and rigidity. This could be through interference with normal parathyroid function, as previously investigated by us (Barbeau and RaymondTremblay, 1965) and by Berger and Ross (1981). These new clues to possible metabolic defects (hyperthyroidism in dominant essential tremor related parkinsonism and possible hypoparathyroidism in the recessive akineto-rigid syndrome) are presently being studied in much more detail, but because of incomplete epidemiology they should not be considered more than leads to further investigations at this time.

\section{ACKNOWLEDGEMENTS}

The studies reported in this paper were supported by grants from the Medical Research Council of Canada (MT4938), the W. Garfield Weston Foundation, the United
Parkinson Foundation and the Fondation Parkinson du Québec. The authors would like to thank Miss Suzanne Paris, R.N. and Miss Anne-Rose Goldin for their help; Miss Isabelle Morin for the art work and Mrs. Hélène LebrunCrête for typing the manuscript.

\section{REFERENCES}

Allan, W. (1937). Inheritance of the Shaking Palsy. Arch. Int. Med. 60: 424-436.

Barbeau, A. and Pourcher, E. (1982). New Data on the Genetics of Parkinson's Disease. Can. J. Neurol. Sci. 9: 53-60.

Barbeau, A. and Raymond-Tremblay, D. (1965). Recent biochemical studies in Parkinson's disease and position of the problem. In: Parkinson's Disease - Trends in Research and Treatment. (Ed. A. Barbeau; L. Doshay and E.A. Spiegel). Grune and Stratton, pp. 79-94.

Berger, J.R. and Ross, D.B. (1981). Reversible Parkinson Syndrome complicating post-operative hypoparathyroidism. Neurology (NY) 31:881-882.

Kondo, K., Kurland, L.T. and Schull, W.J. (1973). Parkinson's disease. Genetic Analysis and Evidence of a Multifactorial Etiology. Mayo Clinic Proc. 48: 465-475.

Martilla, R.J. and Rinne, U.K. (1976). Epidemiology of Parkinson's disease in Finland. Acta Neurol. Scandinav. 53: 81-102.

Martin, W.E., Yound, W.I. and Anderson, V.E. (1973). Parkinson's Disease - A genetic study. Brain 96: 495506.

Mjönes, H. (1949). Paralysis Agitans: A clinical and genetic study. Acta Psychiat. Scand. (Suppl. 54) p. 1-130.

Perry, T.L., Bratty, P.J.A., Hansen, S., Kennedy, J., Urquhart, N. and Dolman, C.L. (1975). Hereditary mental depression and Parkinsonism with taurine deficiency. Arch. Neurol. 32: 108-113.

Romanul, F.C.A., Fowler, H.L. and Radvany, J. (1977). Azorean disease of the nervous system. New England J. Med. 296: 1505-1508.

Tune, L.E., Folstein, M., Rabins, P., Jayaram, G. and McHugh, P. (1982). Familial manic-depressive illness and familial Parkinson's disease: - a case report. Johns Hopkins Med. 151: 65-70.

Yokochi, M. and Narabayashi, H. (1981). Clinical characteristics of juvenile Parkinsonism. In: Research Progress in Parkinson's disease. (Rose, F.C. and Capildeo, R., Editors). Pitman Medical, Kent, Great Britian. pp. 35-39. 